$$
\angle A-U R=-98-433
$$

\title{
TEST PLAN FOR HYDROGEN GETTERS PROJECT
}

April 1, 1998

Project Number 5061.06.0202

RECEIVED

JUL 01998

Q.STI

Prepared by:

Gene Mroz

Los Alamos National Laboratory

Jeff Weinrach

Environmental Chemist

Benchmark Environmental Corporation 4501 Indian School Road NE, Suite 105

Albuquerque, New Mexico 87110

Prepared under Subcontract Number B45370007-8T for:

Los Alamos National Laboratory

Los Alamos, New Mexico 87545 


\section{DISCLAIMER}

This report was prepared as an account of work sponsored by an agency of the United States Government. Neither the United States Government nor any agency thereof, nor any of their employees, makes any warranty, express or implied, or assumes any legal liability or responsibility for the accuracy, completeness, or usefulness of any information, apparatus, product, or process disclosed, or represents that its use would not infringe privately owned rights. Reference herein to any specific commercial product, process, or service by trade name, trademark, manufacturer, or otherwise does not necessarily constitute or imply its endorsement, recommendation, or favoring by the United States Government or any agency thereof. The views and opinions of authors expressed herein do not necessarily state or reflect those of the United States Government or any agency thereof. 


\section{DISCLAIMER}

Portions of this document may be illegible electronic image products. Images are produced from the best available original document. 


\section{TEST PLAN FOR HYDROGEN GETTERS PROJECT}

April 1, 1998

Project Number 5061.06.0202

Prepared by:

Gene Mroz

Los Alamos National Laboratory

Jeff Weinrach

Environmental Chemist

Benchmark Environmental Corporation 4501 Indian School Road NE, Suite 105

Albuquerque, New Mexico 87110

Prepared under Subcontract Number B45370007-8T for:

Los Alamos National Laboratory

Los Alamos, New Mexico 87545 


\section{CONTENTS}

Section

Page

ACRONYMS AND ABBREVIATIONS

iv

1.0 SUMMARY

2.0 BACKGROUND

2.1 Statement of Mixed Waste Treatment Need

2.2 Technology Concept and Function

2.3 Current Status or State of Development

2.4 Technology Improvements

3.0 REQUIRED DATA AND ACQUISITION APPROACH . 4

4.0 TEST OBJECTIVES

4.1 Design Data Objectives $\quad 5$

4.2 Operating Data Objectives $\quad 5$

4.3 Regulatory Strategy Data Objectives $\quad 5$

5.0 DATA QUALITY OBJECTIVES

$\begin{array}{lll}6.0 & \text { DATA ACQUISITION DESIGN } & 7\end{array}$

6.1 Identification of Point Data Sets 7

6.2 Specification for Obtaining Data for Each Data Set 7

6.3 Formulation of Data Quality Requirements for Each Data Set 7

6.4 Preparation of Data Requirements Package for Each Technical Objective $\quad 8$

$\begin{array}{llr}7.0 & \text { DESIGN OF EXPERIMENTS } & 8\end{array}$

7.1 Experimental Design $\quad 8$

$\begin{array}{llr}7.2 & \text { Equipment Design } & 9\end{array}$

8.0 INSTRUMENTATION, PROCESS MONITORING, AND CONTROL DESIGN 10

$\begin{array}{lll}9.0 & \text { RUN PLAN SUMMARY } & 10\end{array}$

9.1 Operations Plan 10

$\begin{array}{ll}9.2 \text { Data Acquisition and Sampling Plan } & 10\end{array}$

$\begin{array}{lll}10.0 & \text { DATA ANALYSIS } & 12\end{array}$

$\begin{array}{lll}11.0 & \text { SUPPORT REQUIREMENTS } & 12\end{array}$

$\begin{array}{lll}12.0 & \text { REFERENCES } & 13\end{array}$ 


\section{LIST OF TABLES}

Table

Page

3-1 Weighted Average Concentrations of Headspace Gases

\section{LIST OF FIGURES}

Figure

Page

2-1 Structure of 1,4-bis(phenylethynyl)benzene

8-1 Process Flow Diagram 


\section{ACRONYMS AND ABBREVIATIONS}

$\begin{array}{ll}\text { DEB } & \text { l,4-bis(phenylethynyl)benzene } \\ \text { DOE } & \text { U.S. Department of Energy } \\ \text { LANL } & \text { Los Alamos National Laboratory } \\ \text { MDP } & \text { Matrix Depletion Program } \\ \text { NIST } & \text { National Institute of Standards and Technology } \\ \text { NRC } & \text { U.S. Nuclear Regulatory Commission } \\ \text { RTV } & \text { room temperature-vulcanizing } \\ \text { TRU } & \text { transuranic } \\ \text { TRUPACT-II } & \begin{array}{l}\text { Transuranic Package Transporter-II } \\ \text { TRUPACT-II SARP }\end{array} \\ \text { Safety Analysis Report for TRUPACT-II Shipping Package (NRC 1996) } \\ \text { VOC } & \text { volatile organic compound } \\ \text { WIPP } & \text { Waste Isolation Pilot Plant }\end{array}$




\subsection{SUMMARY}

Hydrogen levels in many transuranic (TRU) waste drums are above the compliance threshold, therefore deeming the drums non-shippable to the Waste Isolation Pilot Plant (WIPP). Hydrogen getters (alkynes and dialkynes) are known to react irreversibly with hydrogen in the presence of certain catalysts. The primary purpose of this investigation is to ascertain the effectiveness of a hydrogen getter in an environment that contains gaseous compounds commonly found in the headspace of drums containing TRU waste. It is not known whether the volatile organic compounds (VOCs) commonly found in the headspace of TRU waste drums will inhibit ("poison") the effectiveness of the hydrogen getter.

The results of this study will be used to assess the feasibility of a hydrogen-getter system, which is capable of removing hydrogen from the payload containers or the Transuranic Package TransporterII (TRUPACT-II) inner containment vessel to increase the quantity of TRU waste that can be shipped to the WIPP.

Experiments will be carried out by passing mixtures of hydrogen with potential poisons through a chamber containing the getter material at a known flow rate. A hydrogen analyzer will be used to measure the amount of hydrogen exiting the chamber as a function of time. From the incoming hydrogen concentration, flow rate, theoretical (stoichiometric) capacity for the getter, and the hydrogen concentration vs. time data, the effectiveness of DEB in the removal of hydrogen can be demonstrated.

If a component of the mixture is, in fact, competing with hydrogen for the getter, the hydrogen concentration versus time data for the mixture will have discernible differences compared with the poison-free environment. Based on these comparisons, a qualitative decision will be made as to whether the particular mixture contains a poison. A kinetic model will be used to determine the effects of flow rate, partial pressure of hydrogen, temperature, and initial amount of getter on the hydrogen concentration versus time data. If the qualitative analysis becomes ambiguous, then the model will be used to quantify the poisoning effects. Tests will be conducted at selected temperatures within the envelope specified by the Safety Analysis Report for TRUPACT-II Shipping Container (TRUPACT-II SARP) (U.S. Nuclear Regulatory Commission [NRC] 1996) $\left(-29^{\circ} \mathrm{C}\left[-20^{\circ} \mathrm{F}\right]\right.$ to $60^{\circ} \mathrm{C}$ $\left.\left[140^{\circ} \mathrm{F}\right]\right)$.

Approximately 35 VOCs have been identified as being present in TRU waste, most of which are common organic solvents (e.g., carbon tetrachloride and methanol). Several other compounds (e.g., hydrogen sulfide and $\mathrm{HCl}$ ) not observed in TRUPACT-II container headspace may, if present, poison the getter.

To minimize the number of experiments, the compounds will be grouped based on their structure and chemistry. Compounds within a particular group with the greatest probability to poison the getter will first be tested. If poisoning does not occur, it can be concluded that the particular group of compounds does not poison the getter.

\subsection{BACKGROUND}

\subsection{Statement of Mixed Waste Treatment Need}

Approximately 9,000 of the $\sim 23,000$ TRU waste drums at Los Alamos National Laboratory (LANL) are currently unshippable to the WIPP because they exceed the wattage (decay heat) limits, as specified in the TRUPACT-II SARP (NRC 1996). These limits are derived from worst-case 
calculations of the amount of hydrogen expected to be generated within the innermost bag by radiolysis during a 60 -day shipping period.

Of the $\sim 9,000$ unshippable TRU drums at LANL, about 3,000 exceed wattage limits by less than a factor of 3. The Matrix Depletion Project (MDP) is expected to result in raising the wattage limits by a factor of about 3 , in which case these drums would be deemed shippable.

About 3,000 drums exceed wattage limits by between 3 and 12 times. For these drums, the proposed plan is to open the drums, release the accumulated hydrogen through piercing of plastic bag confinement layers, and reclose the drums to meet wattage limits. This process will not generate additional drums for disposal.

The remaining $\sim 3,000$ drums, which exceed wattage limits by more than 12 times, would still exceed wattage limits even if inner layer elimination reduced the resistance to hydrogen transport. The drum contents would need to be divided amongst a number of drums to bring individual container wattage limits to acceptable levels. For the $\sim 200$ drums whose wattage limits are exceeded by $>84$ times, hundreds of drums would be needed to store the separated contents. This increase in drums would result in significantly greater handling costs and greater TRU waste volumes.

Treatment facilities, if and when they are built, would also be expensive options. One estimate shows that it would cost $\sim \$ 1,300$ per drum (U.S. Department of Energy [DOE] 1995) to treat TRU waste at a facility proposed for the Idaho National Engineering and Environmental Laboratory.

Hydrogen getters would be used to reduce the hydrogen levels in the drums whose wattage limits exceed 12 times. This would reduce the number of additional drums generated by repackaging by over 2,600 drums. For each drum, a cost of between $\$ 30$ and $\$ 300$ would be needed to introduce the getter to remove the gaseous hydrogen. Using a cost estimate of $\$ 10,000$ per drum to treat, repackage, characterize, certify, transport, and emplace a drum of TRU waste at the WIPP, this technology can save the program over $\$ 23$ million at LANL alone.

\subsection{Technology Concept and Function}

Hydrogen getters are solid materials that irreversibly scavenge hydrogen from the gas phase and chemically bind it in the solid state. They belong to a class of compounds called alkynes, which are characterized by the presence of carbon-carbon triple bonds. The triply-bonded carbon atoms in alkyne compounds will, in the presence of suitable catalysts such as palladium (Pd), irreversibly react with hydrogen to form the corresponding saturated alkane compounds.

Hydrogen getters of this class were originally developed for use in nuclear weapons by Sandia National Laboratory and the Kansas City Division of Allied-Signal. The getters were used to protect electronic components in sealed assemblies from hydrogen corrosion and are currently being used to provide secondary confinement for tritium shipping containers.

Many compounds and formulations have been tested (Sheppod et al. 1989; Smith and Sheppod 1990). The best performance has been achieved with 1,4-bis(phenylethynyl)benzene (DEB) (Figure 2-1). DEB is a nontoxic, nonmutagenic, crystalline solid. Because DEB is a dialkyne (containing two triple bonds), one mole of DEB reacts with 4 moles of hydrogen ( 2 moles react to form corresponding dialkene, an additional 2 moles react to form dialkane). DEB melts at $179^{\circ} \mathrm{C}$, whereas the fully hydrogenated product melts at $87^{\circ} \mathrm{C}$. The standard formulation for the DEB getter is a mixture of 75 percent $\mathrm{DEB}$ and 25 percent carbon catalyst (5 percent $\mathrm{Pd}$ on carbon). The production process is quite simple: the two materials are mixed together in a ceramic jar mill for several hours after which the DEB getter is ready for use. It has been shown to be stable in the absence of hydrogen for up to 18 months (at $70^{\circ} \mathrm{C}$, under $\mathrm{N}_{2}$ ). 


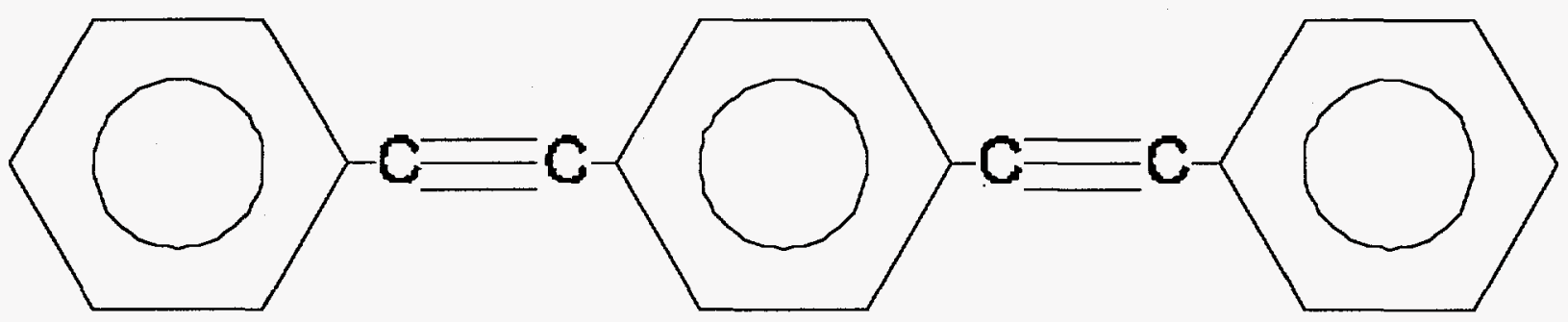

Figure 2-1. Structure of 1,4-bis(phenylethynyl)benzene

The DEB getter reacts rapidly, exothermically $\left(\sim 30 \mathrm{kcal} / \mathrm{mole} \mathrm{H}_{2}\right)$, and irreversibly with hydrogen. It has a capacity of 240 to $330 \mathrm{~cm}^{3}$ hydrogen per gram. The reaction is nearly stoichiometric and proceeds to $>90$ percent of the theoretical capacity. In experiments in a nitrogen atmosphere with a hydrogen addition rate of about $10^{-3} \mathrm{~cm}^{3} / \mathrm{sec}$, the hydrogen concentration was maintained at less than $5 \mathrm{ppm}$ until the getter had reacted with $>90$ percent of its theoretical capacity. The reaction rate with hydrogen is temperature- dependent and proceeds more rapidly as the temperature is increased.

In the presence of oxygen, recombination reactions on the $\mathrm{Pd}$ catalyst will produce water in addition to hydrogenating the dialkyne. Thus, the material acts as both a getter and recombiner in the presence of air. The getters also have been found to be hygroscopic in air environments.

\subsection{Current Status or State of Development}

The DEB formulation has been successfully incorporated into several forms, including powder, pellets, shaped polyethylene composite, a urethane adhesive film, and a castable room temperaturevulcanizing (RTV) silicone. The material has been in regular production for use in DOE components and assemblies since 1977.

Several studies carried out at the Allied-Signal Kansas City Plant (Schicker et al. 1995) addressed the effectiveness of the getters in removing hydrogen under controlled conditions. A number of gases, including $\mathrm{CO}, \mathrm{N}_{2} \mathrm{O}$ and $\mathrm{NH}_{3}$, were subjected to the getters with hydrogen and nitrogen gas present. $\mathrm{N}_{2} \mathrm{O}$ and $\mathrm{NH}_{3}$ did not affect the performance of the catalyst. Carbon monoxide at a concentration of 1 percent was found to reduce the rate of reaction somewhat, but not to irreversibly poison the catalyst. These experiments did not address any VOCs present in TRU waste headspace gases.

The DOE Stockpile Stewardship Program has a number of projects currently being funded addressing the reactivity and characterization of getters. At a recent Joint Working Group (JOWOG) meeting in Livermore, California, a number of papers on getters including DEB were presented including two papers addressing this project. As a result of the workshop, the project team will be able to coordinate their kinetic studies with complimentary studies supported by Stockpile Stewardship. This will provide a significant forum to address poisoning issues as well as engineering issues when that phase of the project is developed.

\subsection{Technology Improvements}


DEB has been proven reliable in reacting irreversibly with hydrogen gas. To justify the use of DEB for removing hydrogen from the headspace of TRU waste, DEB must be demonstrated to be effective in the presence of other gases also known to be present in TRU waste.

If these tests demonstrate the effectiveness of DEB, further improvements to DEB technology will need to be addressed during the next phase of the project. The next phase will focus on engineering aspects (physical form, amount, location of placement) related to actual use for TRU waste shipments.

\subsection{REQUIRED DATA AND ACQUISITION APPROACH}

For these experiments, the critical measure is whether DEB removes hydrogen gas with equivalent effectiveness in both the presence and the absence of selected test gases which are potential poisons. A known mixture of hydrogen and other gases often found in TRUPACT-II containers will pass through a packed bed of getter material. The concentration of hydrogen passing through the getter material will be measured as a function of time by an electrochemical sensor. The effectiveness of the getter will be measured for gas mixtures where the test gas is both present and absent under identical conditions of hydrogen gas concentration, temperature, and flowrate. A comparison of the hydrogen concentration versus time curves for the two cases (test gas absent vs. test gas present) will provide a simple qualitative indication of whether poisoning occurred. The three possible outcomes of comparisons are described below:

If hydrogen concentration versus time curves are the same when test gas is absent versus when test gas is present, then test gas is NOT a poison.

If hydrogen concentration versus time curves are obviously different when test gas is absent versus when test gas is present then test gas IS a poison. The two possible mechanistic options are that the poison is reducing the capacity of DEB by irreversibly binding catalyst sites or the poison is inhibiting the rate of reaction but the DEB capacity is maintained. The kinetic model can be used to distinguish between these two effects and provide semi-quantitative estimates of the magnitudes of these effects. In this case, further experiments can be carried out in which test gas can be pre-loaded prior to introduction of hydrogen gas into the reaction chamber. This would more closely resemble the model's differentiation between reducing DEB capacity and reducing rates.

If hydrogen concentration versus time curves are similar but not identical when test gas is absent versus when test gas is present, the model can be used to evaluate whether the effect is significant in the context of experimentally-determined variability of getter performance.

Choices of mixture composition will be made based on known components of TRUPACT-II container headspace and their concentrations as well as the probability of poisoning the getters based on their chemical properties. The known headspace gases and their weighted average concentrations are shown in Table 3-1. A more detailed discussion regarding the choice of compounds to be tested is presented in the Experimental Design section of the Test Plan.

\subsection{TEST OBJECTIVES}

\subsection{Design Data Objectives}


The primary design data objective is to obtain getter effectiveness as a function of gas mixture composition.

\subsection{Operating Data Objectives}

Not applicable.

\subsection{Regulatory Strategy Data Objectives}

Not applicable.

\subsection{DATA QUALITY OBJECTIVES}

Initially, qualitative comparisons of gas mixtures with pure hydrogen/nitrogen gas will be used to determine whether the mixtures contain poisons. If the qualitative comparisons become ambiguous, then the kinetic model developed for these experiments will be used to quantify the poisoning effects. Once the kinetic model has been tested on sample runs, a precision band will be added to the control experiments to be used as a range through which potentially poisoned samples will be tested. 
Table 3-1. Weighted Average Concentrations of Headspace Gases

\begin{tabular}{|c|c|c|c|c|}
\hline Constituent & $\begin{array}{l}\text { \# of } \\
\text { Drums }\end{array}$ & $\underset{(\mathrm{ppmv})}{\operatorname{Min}}$ & $\underset{(\operatorname{ppmv})}{\operatorname{Max}}$ & $\begin{array}{l}\text { Weighted Avg } \\
\text { (ppmv) }\end{array}$ \\
\hline $1,1,1$-Trichloroethane & 676 & $3.00 \mathrm{E}-02$ & $2.10 \mathrm{E}+04$ & $3.38 \mathrm{E}+02$ \\
\hline $1,1,2,2-$ Tetrachloroethane & 9 & $1.90 \mathrm{E}-01$ & $9.90 \mathrm{E}+00$ & $1.04 \mathrm{E}+00$ \\
\hline $\begin{array}{l}\text { 1,1,2-Trichloro-1,2,2- } \\
\text { trifluoroethane }\end{array}$ & 321 & $2.00 \mathrm{E}-02$ & $1.20 \mathrm{E}+04$ & $3.44 \mathrm{E}+01$ \\
\hline 1,1-Dichloroethane & 130 & $1.80 \mathrm{E}-02$ & $5.80 \mathrm{E}+01$ & $1.99 \mathrm{E}+00$ \\
\hline 1,1-Dichloroethylene & 153 & $2.00 \mathrm{E}-02$ & $8.80 \mathrm{E}+02$ & $1.74 \mathrm{E}+01$ \\
\hline 1,2,4-Trimethylbenzene & 70 & $1.00 \mathrm{E}-02$ & $1.63 \mathrm{E}+01$ & $9.97 \mathrm{E}-01$ \\
\hline 1,2-Dichloroethane & 83 & $1.00 \mathrm{E}-02$ & 4. $10 \mathrm{E}+00$ & $3.69 \mathrm{E}-01$ \\
\hline 1,3,5-Trimethylbenzene & 49 & $6.60 \mathrm{E}-03$ & $1.06 \mathrm{E}+01$ & $7.44 \mathrm{E}-01$ \\
\hline Butanol & 87 & $5.10 \mathrm{E}-01$ & $2.17 \mathrm{E}+03$ & $4.53 \mathrm{E}+01$ \\
\hline Methyl ethyl ketone & 79 & $5.00 \mathrm{E}-01$ & $1.66 \mathrm{E}+02$ & $5.47 \mathrm{E}+00$ \\
\hline Methyl isobutyl ketone & 23 & $6.80 \mathrm{E}-01$ & $7.26 \mathrm{E}+02$ & $5.01 \mathrm{E}+01$ \\
\hline Acetone & 178 & $5.00 \mathrm{E}-01$ & $8.44 \mathrm{E}+02$ & $2.38 \mathrm{E}+01$ \\
\hline Benzene & 250 & $1.60 \mathrm{E}-02$ & $3.98 \mathrm{E}+01$ & $1.09 \mathrm{E}+00$ \\
\hline Bromoform & 1 & $2.20 \mathrm{E}-01$ & $2.20 \mathrm{E}-01$ & $2.24 \mathrm{E}-03$ \\
\hline Chloroform & 192 & $1.00 \mathrm{E}-02$ & $2.07 \mathrm{E}+03$ & $3.59 \mathrm{E}+01$ \\
\hline Carbon Tetrachloride & 485 & $2.00 \mathrm{E}-02$ & $4.30 \mathrm{E}+04$ & $4.23 \mathrm{E}+02$ \\
\hline Chlorobenzene & 2 & $2.30 \mathrm{E}-02$ & $3.40 \mathrm{E}-01$ & $4.54 \mathrm{E}-03$ \\
\hline (cis)-1,2-Dichloroethylene & 22 & $2.00 \mathrm{E}-02$ & $2.60 \mathrm{E}+00$ & $5.74 \mathrm{E}-01$ \\
\hline Cyclohexane & 222 & $3.00 \mathrm{E}-02$ & $1.92 \mathrm{E}+03$ & $8.87 \mathrm{E}+01$ \\
\hline Ethyl benzene & 100 & $1.00 \mathrm{E}-02$ & $2.00 \mathrm{E}+03$ & $2.32 \mathrm{E}+01$ \\
\hline Ethyl ether & 1 & $1.90 \mathrm{E}-01$ & $1.90 \mathrm{E}-01$ & $3.25 \mathrm{E}-02$ \\
\hline Methanol & 195 & $1.38 \mathrm{E}+00$ & $3.02 \mathrm{E}+04$ & $2.61 E+02$ \\
\hline Methylene chloride & 432 & $2.00 \mathrm{E}-02$ & $1.80 \mathrm{E}+05$ & $6.98 \mathrm{E}+02$ \\
\hline o-Xylene & 99 & $1.00 \mathrm{E}-02$ & $2.76 \mathrm{E}+03$ & $5.04 \mathrm{E}+01$ \\
\hline $\mathrm{p} / \mathrm{m}$-Xylene & 200 & $9.80 \mathrm{E}-03$ & $8.50 \mathrm{E}+03$ & $4.55 \mathrm{E}+01$ \\
\hline Tetrachloroethylene & 76 & $1.00 \mathrm{E}-02$ & $3.40 \mathrm{E}+02$ & $5.81 \mathrm{E}+00$ \\
\hline Toluene & 734 & $2.00 \mathrm{E}-02$ & $1.49 \mathrm{E}+03$ & $1.33 \mathrm{E}+01$ \\
\hline Trichloroethylene & 270 & $1.00 \mathrm{E}-02$ & $1.82 \mathrm{E}+03$ & $7.20 \mathrm{E}+01$ \\
\hline Carbon Monoxide & unknown & & & \\
\hline Hydrogen & unknown & & & \\
\hline Methane & unknown & & & \\
\hline $\mathrm{HCl}$ & unknown & & & \\
\hline $\mathrm{NO}_{\mathrm{x}}$ & unknown & & & \\
\hline Hydrogen Sulfides & unknown & & & \\
\hline
\end{tabular}




\subsection{Identification of Point Data Sets}

$\left\{\begin{array}{l}\text { Mixture composition } \\ \text { Temperature }\end{array}\right.$

\subsection{Specification for Obtaining Data for Each Data Set}

All data sets will be collected using the electrochemical hydrogen analysis method described in the equipment design section of the Test Plan.

\subsection{Formulation of Data Quality Requirements for Each Data Set}

The kinetic model (described below) indicates the effect of each input parameter (flow rate, temperature, partial pressure of hydrogen, and initial amount of getter) on the shape of the hydrogen concentration vs. time curve. Sample experiments conducted by adjusting these input parameters shows the same qualitative trends as the model predicts. If a poison or an inhibitor is present in the inlet stream, the shape of the curve should change in a manner comparable to adjusting the rate constants or the initial amount of getter for the individual reaction steps. In order to distinguish between a poison (irreversible) and an inhibitor (reversible), the test constituent can be added prior to the addition of hydrogen and allowed to react to completion. At that point, a poison would have the effect of reducing the amount of available getter to react whereas the inhibitor would only slow the rate of reaction. The model predicts a significant difference in the effect that rate constant changes have on the curves as compared to available getter.

The model assumes a three-stage process: 1) introduction of aliquot of hydrogen gas into reaction zone with getter present, 2) reaction of hydrogen with getter in set time interval, 3) purge of unreacted hydrogen gas to analyzer. Steps 1 and 3 are carried out with no time elapsed in order to more closely model a flow reaction. These three steps are repeated until the amount of hydrogen gas exiting through the chamber reaches a prescribed fraction $(\sim 90 \%)$ of the inlet concentration. The variables that can be adjusted by the programmer are: 1) concentration of hydrogen introduced to the reaction vessel for each cycle, 2) rate constants for four sequential additions of hydrogen molecules to DEB, 3) initial amount of getter in the reaction vessel, and 4) time interval (comparable to contact time in the flow experiment). The areas of interest for the typical theoretical curve are: 1) the initial amount of hydrogen gas analyzed, 2) the time to achieve saturation (or tolerance), and 3) the steepness of the curve. The temperature effects in the experimental data can be modeled by making incremental adjustments to the rate constants.

In the event that comparisons between gas mixtures and pure hydrogen are ambiguous, an error propagation through the model will be used to discern poisoning effects from other potential changes in experimental curves. For example, if input parameters for each poisoning run cannot be held constant, possible changes in the hydrogen concentration curves can occur that are not due to poisoning effects.

\subsection{Preparation of Data Requirements Package for Each Technical Objective}


In the event that precision bands are needed to identify poisoning effects that are relatively small when compared to the control data, the bands will be used to identify poisons for all compounds tested with the same input parameters (temperature, flow rate, etc.). If poisoning data shows dramatic differences compared to the control data, the precision bands will not be used.

\subsection{DESIGN OF EXPERIMENTS}

\subsection{Experimental Design}

A key issue of the experimental design is the selection of compounds from Table 3-1 to be tested. Testing each compound individually is neither cost-effective nor necessary. The compounds can be grouped by common functional groups that will govern their chemical reactivity toward the DEB system. In order of likely decreasing reactivity, the compound classes are

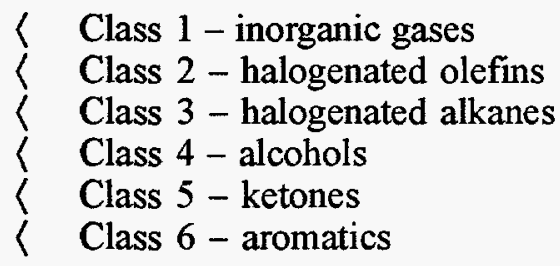

The selection of compounds to test within each class will be based on expected chemical reactivity and molecular structure. A technical advisory panel will aid in the selection of compounds to be tested. One of the initial hypotheses used to determine chemical reactivity with the getter is that increasing the number of chlorine atoms will tend to increase reactivity. Based on initial consultations with the technical advisory panel, the following compounds will be tested first within each category:

$〈 \quad$ inorganic gases $-\mathrm{H}_{2} \mathrm{~S}, \mathrm{HCL}, \mathrm{CO}$

< halogenated olefins - trichloroethylene. Trichloroethylene has been observed in a number of drums and has a high chlorine content. It also is larger than the dichloroethylenes and is, therefore, potentially more sterically hindered.

< halogenated alkanes - carbon tetrachloride

< alcohols - methanol

$<$ ketones - acetone

$<$ aromatics - toluene

Within each class of compounds, the panel will choose the compound most likely to poison DEB. If the selected compound does not poison the DEB, it is reasonable to assume that the remaining compounds in the class will not poison the DEB either. Also, if $\mathrm{HCl}$ does not poison the catalyst, it is unlikely that any chlorinated VOC will poison the catalyst. For completeness, a few tests will be performed on other compounds within that class to verify they are not poisons. If the initial compound tested within a particular class does poison, other compounds will be chosen using the same criteria until a particular compound does not poison. At that point, all compounds within that class not yet tested will not be tested.

Present regulations require that the concentration of flammable VOCs in the inner-most layer of confinement not exceed $500 \mathrm{ppm}$. These initial tests of getter performance in the presence of VOCs 
will be conducted at a VOC concentration of about $1000 \mathrm{ppm}$. If a given VOC adversely affects getter performance at this concentration, we will investigate further the magnitude of concentration effects at lower VOC concentrations.

For a typical mixture experiment with a fixed temperature and amount of getter, the hydrogen analyzer will measure hydrogen concentration passing through the getter as a function of time. If the flow rate is low enough, the initial hydrogen concentration will be zero since all hydrogen available will bind to active sites within the getter material. Once active sites are used up or when the reaction rate drops below the flow rate, the hydrogen concentration will increase until all hydrogen passes through the getter unhindered. The time at which the hydrogen concentration increases sharply will be dependent on the flow rate and the number of active sites available for reaction. With regard to the flow rate, the lower the flow rate the longer the time until catalytic saturation. With regard to the number of active sites, the greater the number of active sites the longer the time until catalytic saturation. The presence of a poison will have the effect of reducing the number of active sites available for reaction which will shorten the amount of time needed to saturate the catalyst. If the poison is reacting with the getter through an equilibrium process, the competition between the getter and hydrogen will be affected by temperature and flow rate. It is critical during these experiments to be able to differentiate between an irreversible poisoning of the getters by headspace gases and a competing reaction with the getters that can be negated by lowering the flow rate or adjusting the temperature accordingly.

Another key issue is performance of DEB in oxygenated versus anoxic environments. Information from personnel at Allied-Signal (Smith 1997) indicates that, in the presence of air, some hydrogen is irreversibly captured by the DEB compound but, in addition, water is produced by the recombination reaction of hydrogen and oxygen on the $\mathrm{Pd}$ catalyst material. The rate of water formation is reported to be faster than that of hydrogenating DEB.

Initially, these experiments will be conducted in a nitrogen carrier gas to avoid the formation of water. This reaction pathway would consume $\mathrm{H}_{2}$ in the presence of oxygen and prevent the determination of the effect of VOCs on the hydrogen capacity of DEB. If initial water absorbed to the getter is observed, samples will either be heated to remove water or will be purged with nitrogen to volatilize water.

Experiments will be also be conducted with potential poisons in the presence of air. The purpose of these experiments would be to confirm that the presence of VOCs does not interfere with the catalytic formation of water nor the uptake of hydrogen by DEB. Some of these experiments will be undertaken at subfreezing temperatures to investigate whether ice formation inhibits hydrogen removal by DEB.

\subsection{Equipment Design}

Preparation of test gas mixtures will be carried out using the Model 340 VICI Metronics Dynacalibrator. This system consists of a diffusion tube containing the compound to be tested in liquid form. Vapor diffuses from the tube at a constant rate defined by the tube's geometry, the tube's temperature, and equilibrium vapor pressure of the liquid in the tube. The diffusion rate is calibrated by gravimetric means. The vapors will then be mixed with a known flow rate of 5 percent $\mathrm{H}_{2}$ in $\mathrm{N}_{2}$ to generate gas mixtures to be tested. If the diffusion tubes do not provide a sufficient vapor pressure, an alternative method of bubbling the five percent $\mathrm{H}_{2}$ in $\mathrm{N}_{2}$ through a flask containing the compounds to be tested will be used. This would permit testing at the saturation partial vapor pressure which is the highest concentration that could be encountered.

Standard features for the VICI Metronics Dynacalibrator include a constant temperature system calibrated against National Institute of Standards and Technology (NIST)-traceable standards to 
ensure set point accuracy to $\pm 0.1^{\circ} \mathrm{C}$, a large permeation chamber, and a flexible flowmetering system. The flowmeter is certified \pm 1 percent accuracy of full scale, NIST-traceable standards.

Hydrogen analysis will be carried out using the Whittaker Hydrogen Analyzer, which uses a diffusion limited electrochemical cell to measure gaseous hydrogen. The range is zero to five percent full scale with zero to twenty percent Standard. Accuracy is \pm 2 percent of full scale with a precision of 0.1 percent of full scale. Response time is 90 percent in two minutes.

The reaction chamber that will be used to create the gas mixtures is a Chromaflex AQ column with an adjustable height bed support. A pressure sensor on the upstream side of the column will be used to establish the appropriate flow regime in which to conduct the experiments.

\subsection{INSTRUMENTATION, PROCESS MONITORING, AND CONTROL DESIGN}

Figure 8-1 provides a process flow diagram for the experiments conducted as a result of this study.

\subsection{RUN PLAN SUMMARY}

\subsection{Operations Plan}

Two kinds of experiments will be conducted:

a) Determination of DEB getter effectiveness in the absence of test compounds

b) Determination of DEB getter effectiveness in the presence of test compounds

The first set of experiments will measure the getter effectiveness in the absence of test compounds. These experiments will be carried out at several different temperatures in the range of $-29^{\circ} \mathrm{C}$ to $60^{\circ} \mathrm{C}$. The next set of experiments will measure getter effectiveness for a number of test gas mixtures containing VOCs selected for testing from Table 2-1. These experiments will be carried out at the same temperatures as above. The getter effectiveness will be evaluated by comparing experiments carried out under the same experimental conditions. The hydrogen concentration versus time curves will be compared for both sets of data and qualitative determinations will be made as to whether poisons are present.

\subsection{Data Acquisition and Sampling Plan}

The data acquisition and sampling plan will be developed once the qualitative effects of poisons is observed in the analyses either through direct poisoning or through changes in input parameters such as initial amount of getter and temperature. The extent of the changes in the curves will determine the number of experiments that need to be conducted for a particular mixture. 


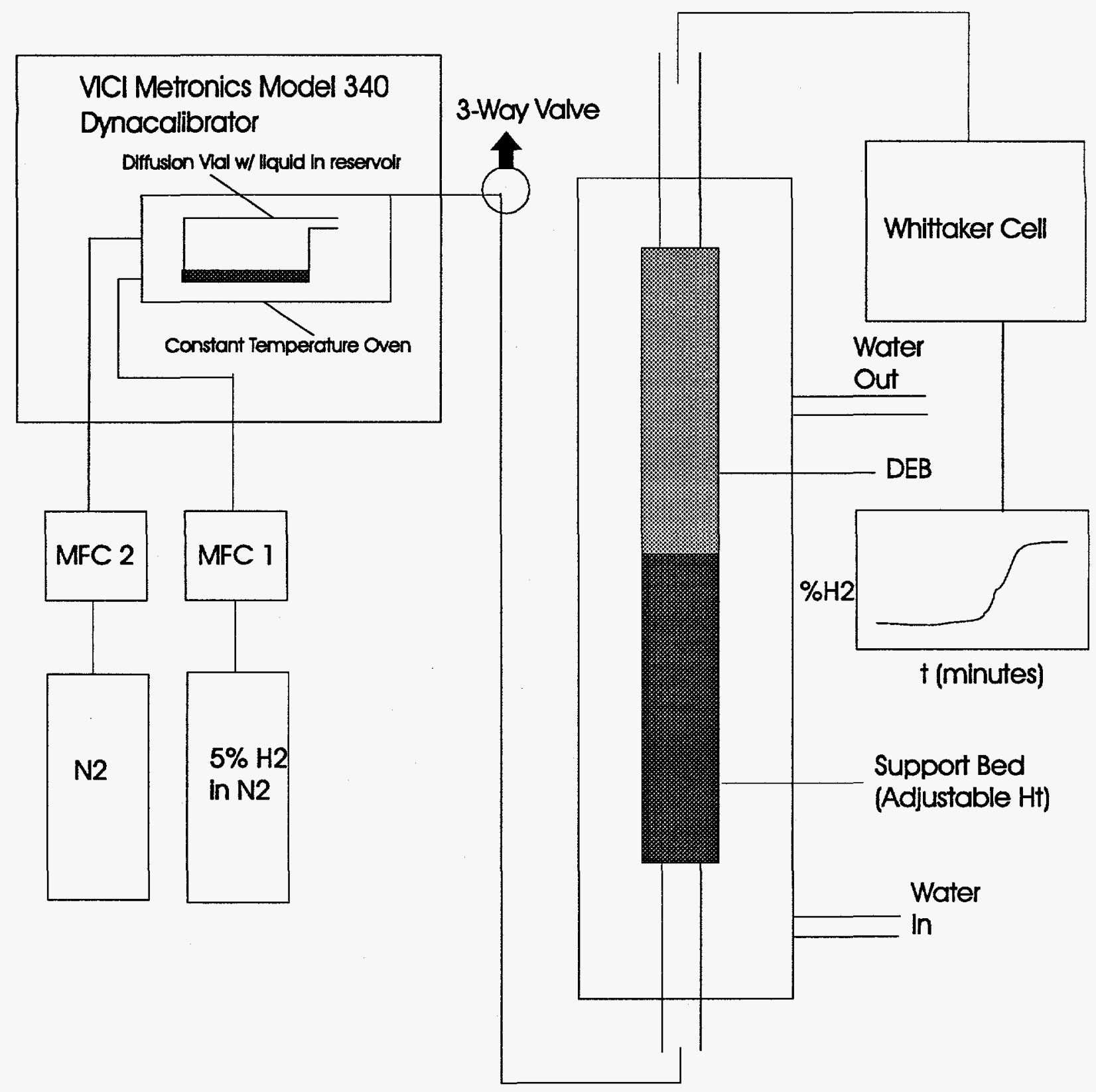

Figure 8-1. Process Flow Diagram 


\subsection{DATA ANALYSIS}

If the adjustments in temperature or in getter concentrations are visually dramatic, then data analysis can be made qualitatively: changes in curve due to introduction of potential poison while hydrogen gas is being bled through chamber is indicative of either poisoning or inhibition effects; effective change in getter concentration with contaminant pre-loaded is indicative of a poison, effective change in rate constants (similar to temperature) with contaminant pre-loaded is indicative of an inhibitor.

\subsection{SUPPORT REQUIREMENTS}

All experiments will be conducted by the LANL Chemical Sciences and Technology Division. The Principal Investigator is Dr. Eugene Mroz ([505]-667-7758, mroz@lanl.gov). Support staff includes trained mechanical, electronics, and chemical technicians as well as undergraduate and graduate student technical assistants.

No special facility requirements are anticipated for carrying out this study. The facility (TA-48, Building RC-1) is a multifunctional chemistry laboratory. The laboratory within this facility (Room 306) is a standard chemistry laboratory equipped with the necessary bench space, fume hoods, and utilities for these experiments.

All gas stream analyses for hydrogen will be conducted on-line, in real time, by an electronic sensor. LANL does not anticipate a need for shipping samples to other laboratories for analysis.

Materials used for these experiments include the following:

〈 DEB Hydrogen Getter. LANL is obtaining this material from the manufacturer, AlliedSignal, Kansas City Plant, and will use their standard formulation of the product which is 75 percent DEB and 25 percent catalyst. The catalyst is 5 percent Pd on carbon. DEB is prepared in powder form (mesh size: -14 to +50 ).

\Certified gas mixture of 5 percent hydrogen in nitrogen. Several commercial sources are available.

( Organic compounds. Small amounts (a few grams) of several different, but readily available, organic compounds will be used to generate test gas mixtures.

The primary waste products will include consumed DEB getter materials and small amounts of unused organic compounds. These will be disposed of in accordance with facility waste management practices.

There will be no need for facility decontamination, decommissioning, or equipment disposal as a result of these experiments.

\subsection{REFERENCES}


DOE. 1995. Evaluation of Feasibility Studies for Private-Sector Treatment of Alpha and TRU Mixed Wastes. DOE/ID-10512, Idaho Falls, Idaho, U.S. Department of Energy, Idaho Operations Office.

NRC. 1996. Safety Analysis Report for the TRUPACT-II Shipping Package. Revision 16, NRC Docket No. 9218, Washington, D.C., U.S. Nuclear Regulatory Commission.

Schicker et al. (J. R. Schicker, D. L. Riley, and H. M. Smith). 1995. "Hydrogen Gas Control Inside Anaerobic Transport Packaging." Presented at the 11th Intemational Conference on Packaging and Transportation of Radioactive Materials, Las Vegas, Nevada, December 3-8, 1995.

Sheppod et al. (T. J. Sheppod, L. R. Gillion, and H. M. Smith). 1989. "Organic Getter Materials for the Removal of Hydrogen and its Isotopes." Presented at the Fourth International Conference on the Effects of Hydrogen on the Behavior of Materials, Moran, Wyoming, September 12-15, 1989.

Smith, H. M. April 25, 1997. Personal communication. Allied-Signal Kansas City Plant, Kansas City, Missouri.

Smith, H. M., and T. J. Sheppod. 1990. "Hydrogen-Tritium Getters and Their Applications." Presented at the Radioluminescent Lighting Technology Transfer Conference, Annapolis, Maryland, September 25-26, 1990. 